\title{
Paediatric Surgery, Mark Davenport and Agostino Pierro (eds)
}

\author{
Oxford University Press, New York, 2009, 451 pp, 1st edn, Plastic-Covered Paperback, \\ \$75.00, ISBN978-0-19-920880-7 (amazon.com)
}

\author{
Graeme John Pitcher
}

Published online: 17 October 2009

(C) Société Internationale de Chirurgie 2009

When one considers the number of children in our communities it is a testament to their robust good health that pediatric surgical pathology occurs so uncommonly and in classical well-described categories of usually rare conditions. In academic pediatric surgical centers around the world, students and junior doctors encounter children with surgical diseases, often learning about the various conditions case by case as they see the various pathologies for the first time. In developing countries and nonacademic environments, nurses, doctors, and general surgeons will occasionally have to treat a child with a surgical problem and will need simple and concise practical guidance.

This book is aimed at filling that niche in the literature on the subject. At a lightweight $4 \times 71 / 4$ inches with a strong plastic-laminated cover in cheerful colors, it would happily travel in the pocket of a student or trainee for the duration of his or her rotation in pediatric surgery. However, $\$ 75$ for a small book of this nature is more than one would expect to pay, and this may be a deterrent to many potential buyers who would "need it only for one rotation." Also, the essential "Britishness" of the book will certainly lessen its appeal on the side of the Atlantic on which it was, paradoxically, published. Its endorsement by the British Association of Paediatric Surgeons is all well and good, but the inclusion of a table of all the past presidents of the association will only serve to amuse most modern readers and remind them of a surgical hubris from years gone by. A truly international book with a broader representation of authors and a

\section{G. J. Pitcher ( $\square)$}

Division of Pediatric Surgery, Department of Surgery,

University of Iowa Hospitals and Clinics, 200 Hawkins Drive,

Iowa City, IA 52242, USA

e-mail: graeme-pitcher@uiowa.edu

URL: www.uihealthcare.com more global view of pediatric surgical problems would surely have served readers and the editors' interests better.

The editors are to be commended for succeeding in creating a book which in my opinion is a very good blend of the concise portability that you would expect in a vade mecum and this book's substantial content. Useful and mainly contemporary references are carried at the end of each section. The spectrum of chapters is comprehensive, including all the usual subjects, as well as urology, cardiac surgery, and some neurosurgery. There is an informative chapter on fetal screening, as well as a useful précis of neonatal medicine. The general considerations chapter refreshingly includes topics such as consent, ethics and withdrawal of care, and even leads the reader to useful electronic resources. However, chapters covering common conditions such as appendicitis and intussusception are so brief as to almost limit their usefulness. A serious omission is the lack of a chapter on head injury, which is presented in a brief half-page in the already severely curtailed chapter on neurosurgery; further, there is no mention of the management of raised intracranial pressure. Criticisms of editorial form include the lack of uniform formatting and writing style between chapterslight-hearted and illustrated with historical vignettes in places and business-like and concise in others. The idea of providing text boxes containing a slogan or quotation as an aide memoir is inconsistently applied, but it is effective in some of the chapters. The use of the inside covers for useful tables providing guidance for fluid management is an excellent device, and one that might be expanded to include some of the vital tables now scattered through the text.

Overall I think this little book would be a worthwhile addition to every surgical trainee's library. It fills a glaring gap in the present literature; but I imagine, like almost everything in these times of hardscrabble consumerism, that it could be better and cheaper! 